Research Paper

\title{
Three-year Review of Bacteriological Profile and Anti- biogram of Burn Wound Isolates in Van, Turkey
}

\author{
Yasemin BAYRAM ${ }^{1}$, Mehmet PARLAK ${ }^{1}$, Cenk AYPAK ${ }^{\circledR}$, İrfan BAYRAM ${ }^{3}$ \\ 1. Microbiology Laboratory, Van Training And Research Hospital, Van, Turkey; \\ 2. Department of Family Medicine, Van Gevas State Hospital, Van, Turkey; \\ 3. Department of Pathology, Faculty of Medicine, University of Yuzuncu Yil, Van, Turkey. \\ $\triangle$ Corresponding author: Dr. Cenk AYPAK, Department of Family Medicine, Van Gevas State Hospital, Van, Turkey. Phone: +90 \\ 5056452780; Fax: +90 432 6122066; E-mail: cenkaypak@yahoo.com.
}

(C) Ivyspring International Publisher. This is an open-access article distributed under the terms of the Creative Commons License (http://creativecommons.org/ licenses/by-nc-nd/3.0/). Reproduction is permitted for personal, noncommercial use, provided that the article is in whole, unmodified, and properly cited.

Received: 2012.06.1I; Accepted: 2012.11.26; Published: 2012.12.07

\begin{abstract}
The risk of infection in burns is well-known. In recent decades, the antimicrobial resistance of bacteria isolated from burn patients has increased. For this reason, a retrospective study was conducted at Van Training and Research Hospital to analyze the bacterial isolates from the wounds of patients admitted to the Burn Unit and to determine the susceptibility patterns of the commonly cultured organisms over a 3-year period, January 2009 to December $201 \mathrm{I}$.

A total of 250 microorganisms were isolated from burn wounds of 179 patients. Our results revealed that the most frequent isolate was Acinetobacter baumannii (23.6\%), Pseudomonas aeruginosa (I2\%), Staphylococcus aureus (II.2\%), Escherichia coli (I0\%) respectively. Multidrug-resistance has emerged as an important concern in our burn unit. Tigecycline, and colistin were found to be the most active drugs against Acinetobacter baumannii. Carbapenems and amikacin, were found to be the most active drugs against other gram negative bacteria. Vancomycin and linezolid were active against gram positive bacteria.

Aggressive infection control measures should be applied to limit the emergence and spread of multidrug-resistant pathogens.
\end{abstract}

Key words: antibiotic, burns, resistance, wounds.

\section{Introduction}

Burns are one of the most common and devastating forms of trauma and a major public health concern in all around the world [1]. The burn patients have unique predisposition to different infections which are linked to impaired resistance from disruption of the skin's mechanical integrity and generalized immune suppression. The skin barrier is replaced by a protein rich, avascular environment that provides a favourable niche for microbial colonization and proliferation. Additionally migration of immune cells is hampered, which contributes to septic process [2-6].

In spite of considerable advances in the last 60 years in antimicrobial treatment, infection still continues to pose the greatest danger to burn patients. It was shown that approximately 73 per cent of all death within the first five days post-burn has been caused by sepsis [7-9]. Also the worldwide emergence of antimicrobial resistance among bacterial pathogens, limits the available therapeutic options for effective treatment of infections [10,11].

Thus, the aim of the current study was to determine the microorganisms and their susceptibility patterns which were isolated from burn wounds of patients at Van Training and Research Hospital in Van, Turkey.

\section{Material and Methods}

\section{Data Collection}

This study was conducted retrospectively at a 10-bed paediatric and adult burn unit located in a 
400-bed tertiary referral hospital. The burn unit is the reference burn center in Van province (with one million inhabitants), Turkey. Consequently patients hospitalized in this unit come from the emergency of the hospital as well as from transfers from other hospitals.

Wound swaps were obtained twice weekly to monitor colonisation and when infection was suspected in the burn unit. All wound specimens were collected by sterile swabs from registered patients. Positive wound swap culture results during a 3-year period (from January 2009 to December 2011) were reviewed and two hundred fifty non-duplicate bacterial species isolated from one hundred seventy-nine patients' wound swabs, were included in the present study.

\section{Assessment and management of burns pa- tients}

Early burn excision and skin grafting is practiced in our burn unit. No routine systemic and topical antimicrobial (e.g. mafenide, silver sulfadiazine) used in our burn unit. Fucidic acid is used as topical agent only during deep excisions.

\section{Bacterial identification and antimicrobial sus- ceptibility}

All samples were inoculated on 5\% sheep blood agar and Eosin methylene blue overnight at $37^{\circ} \mathrm{C}$. Identification of isolates was done by conventional biochemical methods according to Standard microbiological techniques [12]. After determining mainly morphologic criteria of bacteria, panels of automized identification device Phoenix Automated Microbiology System (Becton, Dickinson-USA) was used in order to determine the certain identification and anti-microbial susceptibility rates. Duplicate isolates defined as repeated isolation of the same bacterial species for the same patient with the same profile of antibiotic susceptibility were excluded. Pseudomonas aeruginosa and Acinetobacter spp were accepted as multidrug-resistant if the microorganism was resistant against at least three antimicrobials groups among antipseudomonal cephalosporins, $\beta$-lactam- $\beta$-lactamase inhibitor combination, antipseudomonal fluoroquinolones, antipseudomonal carbapenems or aminoglycosides. The antimicrobial susceptibilities were determined according to the Clinical and Laboratory Standards Institute (CLSI). Information on all bacterial isolates including their antibiotic susceptibility pattern were extracted and processed by SPSS 17.0 software package.

\section{Results}

A total of 250 bacterial isolates were obtained from 179 patients' wound swap over a 3-year period. The most predominant bacterial isolate was Acinetobacter baumannii (A. baumannii) (23.6\%) followed by coagulase negative Staphylococci (13.6\%), Pseudomonas aeruginosa (P. aeruginosa) (12\%), Staphylococcus aureus (S. aureus) $(11.2 \%)$, and Escherichia coli (E. coli) $(10 \%)$ as shown in Table 1.

Table I. Distribution of microorganisms isolated from burn wounds.

\begin{tabular}{lll}
\hline Microorganism & $\mathrm{n}$ & $\%$ \\
\hline Acinetobacter baumannii & 59 & 23.6 \\
Coagulase negative Staphylococci & 34 & 13.6 \\
Pseudomonas aeruginosa & 30 & 12.0 \\
Staphylococcus aureus & 28 & 11.2 \\
Escherichia coli & 25 & 10.0 \\
Enterococcus spp. & 22 & 8.8 \\
Klebsiella pneumoniae & 18 & 7.2 \\
Other Enterobacteriaceae spp. * & 26 & 10.4 \\
Others** & 8 & 3.2 \\
Total & 250 & 100.0 \\
\hline ": 14 Enterobacter spp., 4 Klebsiella oxytoca, 3 Proteus spp., 1 Morganella \\
morgani, 1 Pantoea agglomerans, 1 Proteus mirabilis, 1 Providencia rettgeri, 1 \\
Serratia fonticola. "*: 5 Streptococcus spp., 2 Stenetrophomonas maltophilia, 1 \\
Achromobacter spp..
\end{tabular}

The susceptibility of the organisms to different antibiotics varied depending on the isolate. Although all tested Acinetobacter spp. isolates were sensitive to tigecycline $(\mathrm{n}=37)$ and colistin $(\mathrm{n}=43)$, fifty-five $(93 \%)$ of isolates were multidrug-resistant. Thirteen $(43 \%)$ of $P$. aeruginosa isolates were multidrug-resistant. Meropenem, amikacin, ciprofloxacin and cefepime were found to be most active antimicrobial agents against $P$. aeruginosa. All tested E. coli isolates were susceptible to amikacin $(n=17)$, imipenem $(n=19)$ and meropenem $(n=21)$. Besides these three antimicrobial agents, gentamicin was also found to be in vitro active against Klebsiella pneumonia (K. pneumonia) and other Enterobacteriaceae spp. The antibiotic resistance patterns of gram negative isolates were as shown in Table 2. Extended-spectrum beta-lactamases (ESBL) were found to be 13/25 (52\%) and 7/18 (39\%) among E. coli and K. pneumonia isolates respectively.

Among the $S$. aureus isolated from patients within the burn center, the incidence of methicillin-resistant S. aureus (MRSA) was 19\% and the most active antimicrobial agents were found to be vancomycin and linezolid against $S$. aureus isolates respectively. None of the Enterococcus spp. was found to be resistant to vancomycin. Antimicrobial susceptibilities of gram positive isolates were presented in Table 3. 
Table 2. Susceptibilities of gram negative isolates to various antimicrobials.

\begin{tabular}{|c|c|c|c|c|c|c|c|c|c|c|}
\hline \multirow[b]{2}{*}{ Antimicrobials } & \multicolumn{2}{|c|}{$\begin{array}{l}\text { A. baumannii } \\
\mathrm{n}=59\end{array}$} & \multicolumn{2}{|c|}{$\begin{array}{l}\text { P. aeruginosa } \\
\mathrm{n}=30\end{array}$} & \multicolumn{2}{|c|}{$\begin{array}{l}\text { E. coli } \\
\mathrm{n}=25\end{array}$} & \multicolumn{2}{|c|}{$\begin{array}{l}\text { K. pneumonia } \\
\mathrm{n}=18\end{array}$} & \multicolumn{2}{|c|}{$\begin{array}{l}\text { Other Gram negative microorganisms } \\
n=26\end{array}$} \\
\hline & $n^{*}$ & $\mathbf{R}(\%)$ & $\mathbf{n}^{*}$ & $\mathbf{R}(\%)$ & $\mathbf{n}^{*}$ & R (\%) & $\mathrm{n}^{*}$ & R (\%) & $\mathrm{n}^{*}$ & R (\%) \\
\hline Ceftazidime & 58 & $54(93)$ & 28 & $9(32)$ & 22 & $12(55)$ & 18 & $7(39)$ & 25 & $5(20)$ \\
\hline $\begin{array}{l}\text { Piperacillin/ } \\
\text { tazobactam }\end{array}$ & 57 & $51(90)$ & 29 & $9(31)$ & 24 & $10(42)$ & 17 & $8(47)$ & 24 & $3(13)$ \\
\hline Imipenem & 58 & $50(86)$ & 28 & $13(46)$ & 19 & $0(0)$ & 18 & $0(0)$ & 19 & $1(5)$ \\
\hline Meropenem & 56 & $43(77)$ & 27 & $5(19)$ & 21 & $0(0)$ & 16 & $0(0)$ & 22 & $1(5)$ \\
\hline Gentamicin & 56 & $48(86)$ & 28 & $10(36)$ & 22 & $5(23)$ & 13 & $0(0)$ & 25 & $1(4)$ \\
\hline Cefepime & 55 & $47(86)$ & 24 & $6(25)$ & 22 & $13(59)$ & 15 & $3(20)$ & 25 & $2(8)$ \\
\hline Ciprofloxacin & 59 & $51(86)$ & 28 & $7(25)$ & 25 & $8(32)$ & 18 & $3(17)$ & 26 & $2(8)$ \\
\hline Tigecycline & 37 & $0(0)$ & NT & NT & NT & NT & NT & NT & NT & NT \\
\hline Amikacin & 57 & $30(53)$ & 29 & $6(21)$ & 17 & $0(0)$ & 14 & $0(0)$ & 24 & $2(8)$ \\
\hline Colistin & 43 & $0(0)$ & 20 & $0(0)$ & NT & NT & NT & NT & NT & NT \\
\hline
\end{tabular}

*: number of isolates which were tested, R: resistant, NT: not tested.

Table 3. Susceptibilities of gram positive isolates to various antimicrobials.

\begin{tabular}{|c|c|c|c|c|}
\hline \multirow[b]{2}{*}{ Antimicrobials } & \multicolumn{2}{|c|}{ S. aureus } & \multicolumn{2}{|c|}{ Enterococcus spp. } \\
\hline & $\mathrm{n}=28$ & $\mathrm{R}(\%)$ & $\mathrm{n}=22$ & $\mathrm{R}(\%)$ \\
\hline Penisilin & 26 & $25(96)$ & 9 & $1(11)$ \\
\hline Trimetoprim-Sulfametoksazol & 27 & $2(7)$ & NT & NT \\
\hline Klindamisin & 23 & $1(4)$ & NT & NT \\
\hline Vankomisin & 22 & $0(0)$ & 22 & $0(0)$ \\
\hline Linezolid & 17 & $0(0)$ & 22 & $0(0)$ \\
\hline Daptomisin & 11 & $0(0)$ & 6 & $1(17)$ \\
\hline Ampisilin & NT & NT & 22 & $0(0)$ \\
\hline
\end{tabular}

R: resistant, NT: not tested.

\section{Discussion}

Burn injuries remain a huge public health issue in terms of morbidity and long-term disability throughout the world $[13,14]$. Thermal injury impairs the skin its normal barrier function, thus allowing microbial colonization of the burn wounds. Severe dysfunction of the immune system, a large cutaneous colonization, the possibility of gastrointestinal translocation, a prolonged hospitalization and invasive diagnostic and therapeutic procedures, all contribute to infections $[13,15]$. Patient factors such as age, extent of injury, and depth of burn in combination with microbial factors such as type and number of organisms, enzyme and toxin production, and motility determine the likelihood of invasive burn wound infection. [16]. Although any organism is a potential pathogen in burned patients, coagulase-negative staphylococci and S. aureus and Enterococcus spp. were the most common gram positive pathogens and $P$. aeruginosa, E. coli, K. pneumoniae and Acinetobacter spp. were the most common gram negative microorganisms $[6,17,18]$.

The most common pathogen isolated from burn wounds in our study was Acinetobacter spp. The high prevalence of Acinetobacter baumannii in our centre differs markedly from most other studies from $\mathrm{Eu}-$ rope, the USA and South America [19-21]. Chim et al. have also found Acinetobacter spp. highly prevalent in Singapore and explaned this situation by constant introduction of Acinetobacter spp. carried on human skin (endemic to tropical climate) with every patient admitted in their settings [22]. Other studies have supported the hypothesis that Acinetobacter spp. might be more prevalent in warm climates, with corresponding increase in colonization and nosocomial infection [23-25]. Although our center is placed in eastern part of Turkey where the climate is dry and cold, this hypothesis could be an explanation for our results also and should be further studied.

Our finding concerning the frequency of $P$. aeruginosa $(12 \%)$ was much lower than many previous 
reports where this organism was held responsible for the majority of invasive burn wound infections in burn-treatment facilities [26-29]. S. aureus was the third in the list of microbial isolates recovered in our study. This is contrary to many previous reports indicating a much higher frequency of isolation of this organism [30-31]. In our study, E. coli was the fourth most frequently recovered organism. This is higher than reported by other burn centers [29-32].

The pattern of bacterial resistance is important for epidemiological and clinical purposes. The results of the antimicrobial resistance pattern give serious cause for concern because the predominant bacterial isolates were highly resistant to the commonly available antimicrobial agents in Turkey. Acinetobacter baumannii and $P$. aeruginosa were found to be multidrug-resistant. Despite the increased knowledge of the pathogenesis and antibiotic resistance mechanisms, multidrug-resistant isolates of A. baumanni and $P$. aeruginosa are special concerns in burn care units [33]. The incidence of $A$. baumanni resistant to imipenem (86\%) was high, in contrast to other studies [34-36]. Presence of Acinetobacter spp. as normal skin flora, its easy transmissibility and ability to remain viable in a hospital environment due to its multidrug-resistant status and several other factors have been implicated in the increased incidence of nosocomial infections due to this organism. As reported in other studies [22-25] multidrug-resistant Acinetobacter spp. have emerged as a significant cause of wound infection in our burn unit. The incidence of P. aeruginosa resistant to ceftazidime (32\%), Piperacillin/tazobactam (31\%) and imipenem (46\%) was much higher in our study in contrast to other studies [37, 38]. Also the incidence of methicillin-resistant $S$. aureus (MRSA) was $19 \%$. This is consistent with those reported from other countries [37, 38] and supports the fact that there was increasing evidence that MRSA has become a significant problem. We found that vancomycin, linezolid, and ampicillin were still active drugs for the treatment of Enterococcus fecalis.

The emergence of ESBL producing strains among Enterobacteriaceae (E. coli, K. pneumoniae, E. cloacae and $P$. mirabilis) is a special concern [39]. Guggenheim et al have showed that imipenem and meropenem were the most active antimicrobial agents for ESBL producing strains [40]. Our results were consistent with aforementioned study.

The main limitations of our study are the retrospective design and use of only a single burn center's data. Culture isolates were unavailable for additional testing or molecular analysis to determine if isolates were acquired through nosocomial transmission. Additionally data obtained from electronic patient rec- ords makes it difficult to distinguish infection from colonization. Although it is known that the widespread use of broad spectrum antimicrobials in burn units would provide a fertile ground acquisition of resistance and transformation to form new strains [22], detailed treatment regimens were unavailable in our study and it is unknown what impact antibiotic use had on culture data.

In conclusion, the growth of multidrug-resistant organisms should be considered as a serious risk in burn units. Aggressive infection control measures should be applied to limit the emergence and spread of multidrug-resistant pathogens.

\section{Conflict of interest}

The authors have no conflict of interest to report.

\section{References}

[1] Qader AR, Muhamad JA. Nosocomial infection in sulaimani burn hospital, Iraq. Ann Burns Fire Disasters. 2010; 23(4): 177-81.

[2] Soares de Macedo JL, Santos JB. Nosocomial infections in a Brazilian Burn Unit. Burns. 2006; 32(4): 477-81.

[3] Ahuja RB, Gupta A, Gur R. A prospective double-blinded comparative analysis of Framycetin and Silver Sulphadiazine as topical agents for burn. A pilot study. Burns. 2009; 35(5): 672-6.

[4] Vindenes HA, Ulvested E, Bjerknes R. Concentrations of cytokines in plasma of patients with large burns: their relation to time after injury, burn size, inflammatory variables, infection and outcome. Eur J Surg. 1998; 164(9): 647-56.

[5] Alexander M, Chaudry IH, Schwacha MG. Relationships between burn size, immunosuppresion, and macrophage hyperactivity in a murine model of thermal injury. Cell Immunol. 2002; 220(1): 63-9.

[6] Church D, Elsayed S, Reid O, Winston B, Lindsay R. Burn wound infections. Clin Microbiol Rev. 2006; 19(2): 403-34.

[7] Macedo JLS, Santos JB. Bacterial and fungal colonization of burn wounds. Mem Inst Oswaldo Cruz. 2005; 100(5): 535-39.

[8] Taneja N, Emmanuel R, Chari PS, Sharma M. A prospective study of hospital-acquired infections in burn patients at a tertiary care referral centre in North India. Burns. 2004; 30(7): 665-9.

[9] Vindenal H, Bjerknes R. Microbial colonization of large wounds. Burns. 1995; 21(8): 575-9.

[10] Singh D, Singh A, Sharma AK, Sodhi L. Burn mortality in Chandigarh zone: 25 years autopsy experience from a tertiary care hospital of India. Burns. 1998; 24(2): 150-6.

[11] Sharma BR, Harish D, Singh VP, Bangar S. Septicemia as a cause of death in burns: an autopsy study. Burns. 2006; 32(5): 545-9.

[12] Winn W, Allen S, Janda W, et al. Koneman`s Color Atlas and Textbook of Diagnostic Microbiology. 6th ed. Philadelphia: Lippincott Williams \& Wilkins; 2006.

[13] Mayhall CG. The epidemiology of burn wound infections: then and now. Clin Infect Dis. 2003; 37(4): 543-50.

[14] Rastegar Lari AR, Alaghehbandan R, Akhlaghi L. Burn wound infections and antimicrobial resistance in tehran, iran: an increasing problem. Ann Burns Fire Disasters. 2005; 18(2): 68-73.

[15] Avni T, Levcovich A, Ad-El DD, Leibovici L, Paul M. Prophylactic antibiotics for burns patients: systematic review and meta-analysis. BMJ. 2010; 340: 241.

[16] Pruitt BA Jr, McManus AT, Kim SH, Goodwin CW. Burn wound infections: current status. World J Surg. 1998; 22(2): 135-45.

[17] Revathi G, Puri J, Jain BK. Bacteriology of burns. Burns. 1998; 24(4): 347-9.

[18] Rastegar Lari A, Bahrami Honar H, Alaghehbandan R. Pseudomonas infections in Tohid Burn Center, Iran. Burns. 1998; 24(7): 637-41.

[19] Wurtz R, Karajovic M, Dacumos E, Jovanovic B, Hanumadass M. Nosocomial infections in a burn intensive care unit. Burns. 1995; 21(3): 181-4.

[20] Appelgren P, Björnhagen V, Bragderyd K, Jonsson CE, Ransjö U. A prospective study of infections in burn patients. Burns. 2002; 28(1): 39-46. 
[21] Santucci SG, Gobara S, Santos CR, Fontana C, Levin AS. Infections in a burn intensive care unit: experience of seven years. J Hosp Infect. 2003; 53(1): 6-13.

[22] Chim H, Tan BH, Song C. Five-year review of infections in a burn intensive care unit: High incidence of Acinetobacter baumannii in a tropical climate. Burns. 2007; 33(8): 1008-14.

[23] Siau H, Yuen KY, Ho PL, Wong SSY, Woo PCY. Acinetobacter bacteremia in Hong Kong: prospective study and review. Clin Infect Dis. 1999; 28(1): 26-30.

[24] Fournier PE, Richet H. The epidemiology and control of Acinetobacter baumannii in health care facilities. Clin Infect Dis. 2006; 42(5): 692-9.

[25] McDonald LC, Banerjee SN, Jarvis WR. Seasonal variation in Acinetobacter infection: 1987-1996. Clin Infect Dis. 1999; 29(5): 1133-7.

[26] Lari AR, Alaghehbandan R. Nosocomial infections in an Iranian burn care center. Burns. 2000; 26(8): 737-40.

[27] Song W, Lee KM, Kang HJ, Shin DH, Kim DK. Microbiological aspects of predominant bacteria isolated from the burn patients in Korea. Burns. 2001; 27(2): 136-9.

[28] Gupta AK, Uppal S, Garg R, Gupta A, Pal R. A clinico-epidemiologic study of 892 patients with burn injuries at a tertiary care hospital in Punjab, India. J Emerg Trauma Shock. 2011; 4(1): 7-11.

[29] Rezaei E, Safari H, Naderinasab M, Aliakbarian H. Common pathogens in burn wound and changes in their drug sensitivity. Burns. 2011; 37(5): 805-7.

[30] Sharma BR. Infection in patients with severe burns; cause and prevention thereof. Infect Dis Clin North Am. 2007; 21(3): 745-59.

[31] Hodle AE, Richter KP, Thompson RM. Infection control practices in U.S. burn units. Mol Biol Rep. 2006; 27(2): 142-51.

[32] Ozumba UC, Jiburum BC. Bacteriology of burn wounds in Enugu, Nigeria. Burns. 2000; 26(2): 178-80.

[33] Huan JN, Tang JJ. Drug-resistance Acinetobacter baumannii infection in burn patients: current situation and countermeasure. Zhonghua Shao Shang Za Zhi. 2011; 27(2): 84-7.

[34] Jones RN, Pfaller MA, Doern GV, Erwin ME, Hollis RJ. Antimicrobial activity and spectrum investigation of eight broad-spectrum b-lactam drugs: a 1997 surveillance trial in 102 medical centers in the United States. The Cefepime Study Group. Diagn Microbiol Infect Dis. 1998; 30(3): 215-28.

[35] Stratchounski LS, Kozlov RS, Rechedko GK, Stetsiouk OU, Chavrikova EP. Antimicrobial resistance patterns among aerobic gram-negative bacilli isolated from patients in intensive care unit: results of multicenter study in Russia. The Russian NPRS Study Group. Clin Microbiol Infect. 1998; 4: 497-507.

[36] Hanberger H, Garcia-Rodriguez JA, Gobernado M, Goossens H, Nilsson LE, Struelens MJ. Antibiotic susceptibility among aerobic gram-negative bacilli in intensive care units in 5 European countries. J Am Med Assoc. 1999; 281(1): 67-71.

[37] Lesseva MI, Hadjiiski OG. Staphylococcal infections in the Sofia Burn Centre, Bulgaria. Burns. 1996; 22(4): 279-82.

[38] Spencer RC, Bauernfeind A, Garcia-Rodriguez J, Jarlier V, Pfaller M, Turnidge J et al. Surveillance of the current resistance of nosocomial pathogens to antimicrobials. Clin Microbiol Infect 1997;3:21-35.

[39] Giske CG, Monnet DL, Cars O, Carmeli Y. ReAct-Action on Antibiotic Resistance; Clinical and economic impact of common multidrug-resistant gram-negative bacilli. Antimicrob Agents Chemother. 2008; 52(3): 813-21.

[40] Guggenheim M, Zbinden R, Handschin AE, Gohritz A, Altintas MA, Giovanoli $P$. Changes in bacterial isolates from burn wounds and their antibiograms: a 20-year study (1986-2005). Burns. 2009; 35(4): 553-60. 